\title{
Pancreatitis, Adrenal Insufficiency and Autoimmune Diabetes Mellitus in a girl with probable Sarcoidosis
}

\author{
Carley Frerichs, Renuka Ramakrishnan, Hussain Alsaffar, Urmi Das, Poonam Dharmaraj, \\ Eileen Baildam, Gavin Cleary, Liza McCan, Suneela Nayak, Senthil Senniappan \\ Alder Hey Children's NHS Foundation Trust, Liverpool, United Kingdom
}

\section{Background}

Sarcoidosis is a multisystem disease characterised by abnormal accumulation of inflammatory cells (granulomas). The presentation can be variable. The condition is known to have endocrine manifestations.

\section{Case Report}

A 9-year-old girl of mixed ethnic origin presented with symptomatic hypercalcaemia following a three-month history of weight loss and lethargy. Autoimmune hypothyroidism had been diagnosed 10 months previously. Hypercalcaemia was associated with pancreatitis. She then developed type 1 diabetes. The ACE levels (135 U/I (NR 10-43)) and ESR levels (26-35 mm/hr) were elevated. Conjunctival biopsy did not reveal granulomas and bone marrow biopsy was normal. A probable diagnosis of sarcoidosis was made. She was treated with steroids and methotrexate. A number of endocrine manifestations were present.

\section{Hypercalcaemia}

At initial presentation with lethargy:

- Serum vitamin D concentration was low (11nmol/L) (NR $>50)$

- Cholecalciferol 20,000 units daily for 7 days followed by 800 units daily was commenced

- One month later, her symptoms worsened and she had developed anaemia and renal impairment

- Hypercalcaemia was noted (Table 1)

- Elevated amylase (395u/I) and USS abdomen findings suggested pancreatitis

Table 1: Bone Parameter Results

$\begin{array}{lll}\text { Parameter } & \text { Result } & \text { Normal Range } \\ \begin{array}{l}\text { Corrected } \\ \text { Calcium }\end{array} & 3.7 \mathrm{mmol} / \mathrm{I} & 2.15-2.55 \\ \begin{array}{l}\text { Phosphate } \\ \text { PTH }\end{array} & 1.46 \mathrm{mmol} / \mathrm{I} & 1.45-1.78 \\ \begin{array}{l}0.1 \mathrm{pmol} / \mathrm{I} \\ 1,25 \text { vitamin D3 }\end{array} & 161 \mathrm{pmol} / \mathrm{l} & 43-143 \\ \begin{array}{l}\text { Urine Ca:Creat } \\ \text { ratio }\end{array} & \begin{array}{l}3.03 \mathrm{mmol} / \\ \mathrm{mmol}\end{array} & 0.08-0.79\end{array}$

Intravenous fluids and one dose of calcitonin normalised the calcium concentration. Bisphosphonates were not used due to renal impairment.

\section{Hypercalcaemia in Sarcoidosis}

Elevated levels of 1,25 vitamin D3 are produced by extrarenal 1 - $\alpha$ hydroxylation of vitamin D in alveolar macrophages and sarcoid granulomas (see Figure 1).

\section{Thyroid Disease}

Autoimmune thyroid disease is managed with levothyroxine. Thyroid peroxidase antibodies were positive.
Figure 1: Causes and consequences of abnormal calcium homesostasis in sarcoidosis $^{1}$

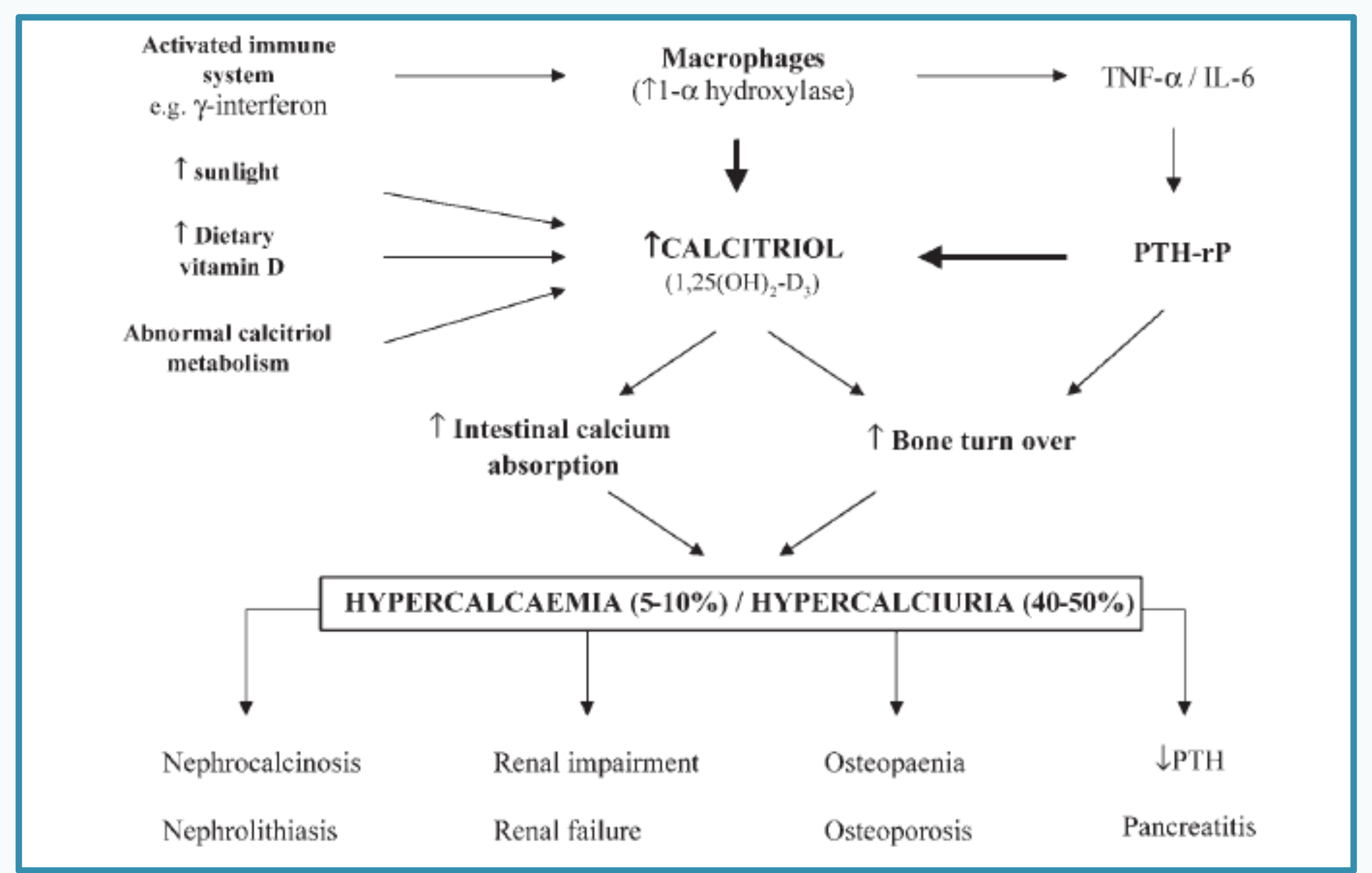

\section{Hypoadrenalism}

- ACTH was undetectable

- Standard synacthen test was suboptimal (cortisol <50 $\mathrm{nmol} / \mathrm{L}$ at 0 mins and $320 \mathrm{nmol} / \mathrm{l}$ at 30 mins)

- MRI pituitary was normal

- Adrenal antibodies negative

- Hydrocortisone was commenced

\section{Diabetes Mellitus}

Within few days of admission, the patient developed diabetes mellitus requiring insulin therapy. Initially this was thought to be related to pancreatitis however persisted. Anti-GAD antibodies were strongly positive (419 U/ml (NR 0-5) and IgG antibodies were $9 \mathrm{mg} / \mathrm{ml}$ (NR 0-5). The patient is on a multiple daily injection regime.

\section{Summary}

- Granulomatous diseases like sarcoidosis are rare causes of hypercalcaemia in children.

- Sarcoidosis can be associated with multiple endocrine problems including hypothalamo-pituitary disease and autoimmune endocrinopathy.

\section{Email: carleyfrerichs@doctors.org.uk}

References

1.Porter N, Beynon HL, Rendeva HS. Endocrine and Reproductive Manifestations of

Sarcoidosis. QJ Med 2003; 96: 553-561 